\title{
TO STUDY THE COMPLICATIONS AND OUTCOMES OF SERUM HIGH SENSITIVITY C-REACTIVE PROTEIN LEVELS \& RISK CATEGORIES IN PATIENTS WITH ATRIAL FIBRILLATION
}

\author{
Natarajan Ramesh ${ }^{1}$, Sappani Kasipandian²
}

${ }_{1}^{1}$ Assistant Professor, Department of General Medicine, Thanjavur Medical College and Hospital, Thanjavur, Tamilnadu, India. 2Professor, Department of General Medicine, Vellammal Medical College Hospital and Research Institute, Madurai, Tamilnadu, India.

\section{ABSTRACT}

\section{BACKGROUND}

Atrial fibrillation (AF) is the most common sustained cardiac arrhythmia necessitating hospitalization and associated with significant rates of morbidity and mortality. ${ }^{1}$ Several haemostatic and inflammatory markers, novel lipid parameters, markers of oxidative stress, and cellular adhesion molecules have been linked to steps in atherogenesis, thrombosis, or cardiovascular disease events like AF.2 But only Serum high sensitivity C-Reactive Protein (Sr. hs-CRP) level and risk category has been shown to add prognostic information over and above that provided by global risk prediction models by the Framingham Risk Score. ${ }^{3}$ So screening of Sr. hs-CRP testing appears to be the most promising of AF.

The aim of this study was to evaluate the value of Sr. hs-CRP levels and hs-CRP risk categories in patients with AF in predicting Cardio Embolic Ischemic Stroke (CEIS) \& other morbidity \& mortality.

\section{MATERIALS AND METHODS}

This study was conducted in 86 patients with AF who attended the General Medicine, Cardiology, Neurology OPDs and got admitted in respective wards in M.G.M. Govt. Hospital \& K.A.P.V. Govt. Medical College, Thiruchirapalli, Tamilnadu during the period April 2016 to February 2017.

\section{RESULTS}

In this study, of the $86 \mathrm{AF}$ patients, 42 (48.8\%) were males and 44 (51.2\%) were females with age between 16 and 86 years. Of this Permanent, Persistent, Paroxysmal and Lone AF was detected in 65 (75.58\%), 17 (19.77\%), 3 (3.49\%) and 1 (1.16\%) patient with the mean and range of Sr. hs-CRP levels of $4.78 \mathrm{mg} / \mathrm{L}$ (1.7 to 9.6$), 4.33 \mathrm{mg} / \mathrm{L}(1.1$ to 8.6$), 0.8 \mathrm{mg} / \mathrm{L} \mathrm{(0.7} \mathrm{to} 0.9)$, and $0.9 \mathrm{mg} / \mathrm{L}(0.9)$ and with the survival vs expired rate of $22(33.85 \%)$ vs $43(66.15 \%), 8(47.06 \%)$ vs $9(52.94 \%), 3(100 \%)$ vs $0(0 \%)$ and 1 (100\%) vs $0(0 \%)$ respectively. High hs-CRP risk category ( $>3 \mathrm{mg} / \mathrm{L})$ was in $65(75.58 \%)$ patients with AF, of which permanent AF in 53 (81.54\%) and persistent AF in $12(18.46 \%)$ patients with survival vs expired rate of $13(24.53 \%)$ vs $40(75.47 \%)$ and 4 (33.33\%) vs $8(66.67 \%)$ respectively. Average hs-CRP risk category (1 to $3 \mathrm{mg} / \mathrm{L}$ ) was in $17(19.77 \%)$ AF patients of which permanent AF in $12(70.59 \%)$ \& persistent AF in 5 (29.41\%) with survival vs Expired rate of 9 (75\%) vs 3 (25\%) and 4 (80\%) vs 1 (20\%) respectively. Mild hs-CRP risk category $(<1 \mathrm{mg} / \mathrm{L})$ was in $4 \mathrm{AF}$ patients with $100 \%$ survival rate of which paroxysmal AF in 3 and Lone AF in 1 patient. In this study, 6 (6.97\%) AF patients recovered fully without any complications and 80 (93.02\%) AF patients had complications of which Congestive Cardiac Failure (CCF) was in 50 (58.14\%), CEIS in 27 (31.39\%), Cardiogenic Shock (CGS) in 19 (22.09\%), Acute Kidney Injury (AKI) in 3 (3.49\%) and Transient Ischemic Attack (TIA) in 2 (2.32\%) respectively.

\section{CONCLUSION}

AF patients with high Sr. hs-CRP levels and high hs-CRP risk categories were associated with increased complications and expired rate, whereas mild, average hs-CRP levels and risk categories were associated with less complications \& good survival rate. So, Sr. hs-CRP can be considered as a modifiable risk factor and biomarker to predict the mortality and complications in patients with AF.

\section{KEY WORDS}

Sr. hs-CRP, AF, CCF, CEIS.

HOW TO CITE THIS ARTICLE: Ramesh N, Kasipandian S. To study the complications and outcomes of serum high sensitivity Creactive protein levels \& risk categories in patients with atrial fibrillation. J. Evolution Med. Dent. Sci. 2019;8(08):472-477, DOI: $10.14260 /$ jemds/2019/105

\section{BACKGROUND}

Approximately $1 \%$ to $2 \%$ of the general population has $\mathrm{AF}^{3}$, and the prevalence of $\mathrm{AF}$ increases with age from $<1 \%$ among persons $<50$ years and up to $9 \%$ for those $>80$ years of age. ${ }^{4}$

'Financial or Other Competing Interest': None.

Submission 22-01-2018, Peer Review 07-02-2019,

Acceptance 14-02-2019, Published 25-02-2019.

Corresponding Author:

Dr. Sappani Kasipandian,

Professor of Medicine, Devi Illam, 3-423-5,

Meenakshi Amman Street, Opp. To Pandi Kovil,

Pandian Nagar, Karupayurani PO, Madurai-625020,

Tamilnadu, India.

E-mail: sankarkasipandian@yahoo.com

DOI: $10.14260 /$ jemds $/ 2019 / 105$

\section{(c) (i) $(9)$}

AF has clinical importance related to, loss of left atrial (LA) contractility, inappropriate Rapid ventricular response (RVR), loss of LA appendage contractility and emptying leading to risk of thrombus formation and subsequent CEIS events. $^{1}$

Cardiac conditions associated with $\mathrm{AF}$ are Rheumatic Valvular Heart Disease (RVHD), Non-Rheumatic Valvular Heart Disease (NRVHD), Coronary Artery Heart Disease (CAHD), Cardiac arrhythmias, acute pericarditis, and Dilated and Hypertrophic cardiomyopathy. Noncardiac conditions associated with AF are Systemic Hypertension (SHT), Diabetes Mellitus (DM), Thyrotoxicosis, Pheochromocytoma, Chronic Obstructive Pulmonary Disease (COPD), Primary Pulmonary Hypertension (PHT), acute pulmonary embolism and acute alcohol intoxication. ${ }^{3}$ 
Electrocardiography (ECG) is the most helpful one for the diagnosis of AF which was characterized by the lack of organized atrial activity and the irregularly irregular ventricular response, as varying $R R$ intervals without discrete $P$ waves, PP interval $(<200 \mathrm{~ms})$ and the chaotic $\mathrm{P}$ wave morphology confirm the presence of $\mathrm{AF}^{1}{ }^{1}$ In $\mathrm{AF}$ the $\mathrm{QRS}$ complex is usually narrow, but it may be wide if aberrant conduction or bundle branch block, left ventricular hypertrophy (LVH) or preexcitation syndromes such as WPW syndrome. ${ }^{5}$

Trans Thoracic Echocardiogram (TTE) can be used to determine the underlying factors responsible for $\mathrm{AF}$, the risk of thromboembolism, and the likelihood of success of cardioversion. However, TTE is unable to reliably detect LA thrombi, that are causative in most cases of CEIS; so it requires Trans Oesophageal Echocardiogram (TEE) imaging 6 which has high sensitivity than TTE.

Reduced LA appendage emptying velocity $\quad<20$ $\mathrm{cm} /$ second), dense LA spontaneous contrast, and complex aortic plaque are the findings on TEE that also increase thromboembolic risk. Thrombi can also occur in right atrium, but it is rare. Echocardiographic predictors, such as LVH, LV dysfunction and LA size $>4.5 \mathrm{~cm}$ are associated with thrombo embolism, with an annual stroke risk of at least $4 \%$ if untreated ${ }^{3}$. The flow velocity within LA appendage is reduced during AF so most thrombi are formed within the LA appendage because of the loss of organized mechanical contraction 4 .

CRP is a pentameric $23 \mathrm{kDa}$ member of the pentraxin family of plasma proteins discovered by Tillett and Francis in 1930.7 Named for its ability to precipitate the Cpolysaccharide of Streptococcus pneumonia. CRP elevation is not specific for atherosclerotic disease alone and can occur with a broad range of inflammatory stimuli such as infection, autoimmune diseases, malignancy, and trauma. CRP is produced predominantly in the liver, next in adipose tissue and vascular smooth muscle cells and endothelial cells. CRP may promote atherothrombosis by inducing the expression of cellular adhesion molecules, suppressing endothelial nitric oxide synthase, and increasing levels of endothelin 1, chemokines, and PAI-1.

The initial utility of CRP for CVD risk assessment was hampered because the threshold of detection of older assays ( $>5 \mathrm{mg} / \mathrm{L}$ ) was above the typical range of CRP levels in the general population. This deficiency was remedied by introducing newer, high sensitivity assays that could detect values within the "normal" range of $<3 \mathrm{mg} / \mathrm{L} .{ }^{8}$ hs-CRP levels were outlined as $<1 \mathrm{mg} / \mathrm{L}$ lower risk; $1-3 \mathrm{mg} / \mathrm{L}$, intermediate (average) risk; $>3 \mathrm{mg} / \mathrm{L}$, higher risk), by the Framingham Risk Score. ${ }^{3}$

\section{Aim of The Study}

To study the value of hs-CRP levels and hs-CRP risk categories in patients with $\mathrm{AF}$ in predicting Cardio Embolic Ischemic Stroke \& other morbidity and mortality.

\section{MATERIALS AND METHODS}

\section{Study Area}

General Medicine, Cardiology, Neurology OPDS and got admitted in respective wards in M.G.M. Govt. Hospital \& K. A. P. V. Govt. Medical college, Thiruchirapalli, Tamilnadu.

\section{Study Population}

This study was conducted in 86 patients with AF. Sample size has been taken based on the convenience of the study

\section{Consent}

Prior written consent was obtained from all the patients included in this study in their own mother tongue.

\section{Study Period and Duration}

From April 2016 to February 2017 - 11 months.

\section{Study Design}

Prospective observational study.

\section{Ethical Committee Approval}

This study was approved by the Ethical Committee of the M.G.M. Govt. Hospital \& K. A. P. V. Govt. Medical College, Thiruchirapalli, Tamilnadu.

\section{Inclusion Criteria}

1. Patients who were known to have AF.

2. Patients who developed AF during their hospital stay.

3. Patients of 16-86 years age groups and both sexes with $\mathrm{AF}$.

\section{Exclusion Criteria}

1. Patients who had evidence of infection.

a. Patients with evidence of inflammatory disorders; eg; rheumatoid arthritis, rheumatic fever, seronegative arthritis, vasculitis syndromes.

b. Patients with evidence of malignant tumours (or) leukemia.

c. Patients with Acute Myocardial Infarction.

\section{Statistical Analysis}

Means, Standard Deviations, and p values were calculated through chi square, Fisher's test unpaired ' $t$ ' test and ANOVA was used. For statistical analysis, SPSS software version 20.0 was used.

\section{Methodology}

12 leads ECG, chest X ray, TTE evaluation i.e., M-Mode, 2-D Echo, Doppler study, TEE.

\section{RESULTS}

In all patients a detailed history, clinical examination was taken with special interest regarding palpitation, dyspnea on exertion, chest pain, syncope, swelling of legs, weakness of limbs, TIA, blood pressures in both limbs, heart rate, heart sounds, cardiac murmurs, peripheral pulse rate, rhythm, volume, pulse deficit were noted. Past history of Rheumatic fever, RVHD, SHT, DM, CAHD, COPD and thyrotoxicosis were carefully noted. Treatment history, particularly intake of antiarrhythmic drugs, anticoagulants, and statins were recorded. Personal history regarding smoking (Numbers per day duration) and alcohol intake, (Quantity, frequency, duration) before the current episode, were recorded.

Sr. hs-CRP level was measured in all patients, on admission, by particle - enhanced turbimetric immunoassay, using BioSystems semiautomated analyser (BioSystems Reagents \& Instruments, Barcelona, Spain. Standard treatment protocols for AF were followed. All survived 
patients were followed up for a period of one month. Complications developed during hospital stay were evaluated and treated accordingly. Death or conversion to sinus rhythm was taken as the primary outcomes.

In this study of the $86 \mathrm{AF}$ patients $42(48.8 \%)$ were males and $44(51.2 \%)$ were females. Age of the patients range from 16 to 86 years, of which $39(45.45 \%)$ were in 31 to 50 years,
$29(33.7 \%)$ in 51-70 years, $13(15.1 \%)$ were below 30 years and only $5(5.8 \%)$ were above 71 years. Of these $86 \mathrm{AF}$ patients, dyspnoea in 72 (83.72\%), palpitation in 64 $(74.42 \%)$, legs swelling in $54(62.79 \%)$, chest pain in 49 (56.97\%), weakness of limbs in $27(31.39 \%)$ and TIA in 2 (2.33\%) patients. Many patients were presented with more than one symptom.

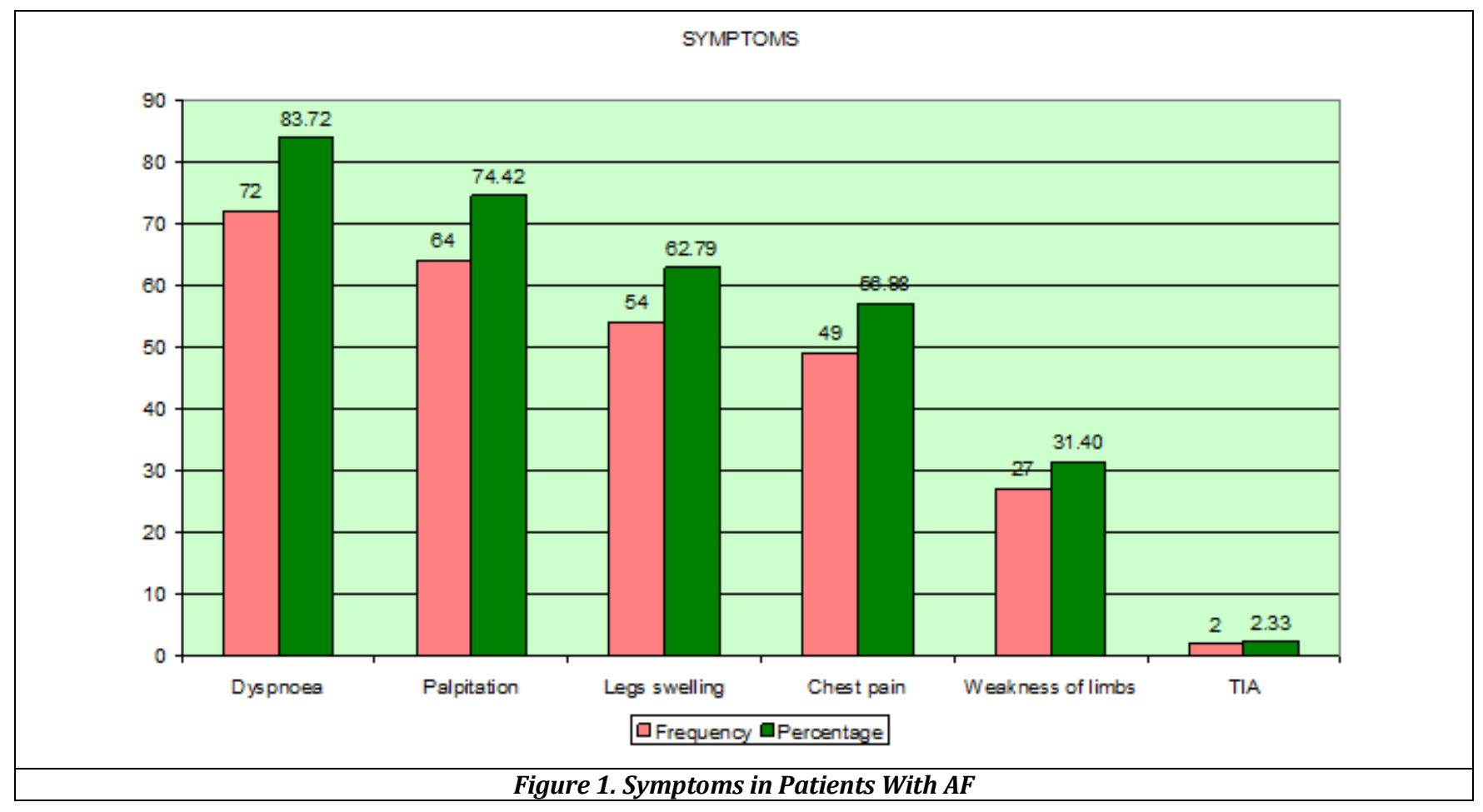

\section{Electrocardiogram (ECG) Findings in AF}

In this study, AF with RVR in 54 (62.79\%), Controlled Ventricular Response (CVR) in 28 (32.55\%), Slow Ventricular Response (SVR) in 4 (4.65\%), atrial flutter along with AF (flutter fibrillation) in 7 (8.13\%), LVH in 36 (41.86\%), ST segment \& T wave changes (IHD) in 22 (25.58\%) patients. Most patients 75 (87.21\%) found to have more than one abnormality in ECG.

\begin{tabular}{|c|c|c|}
\hline ECG Finding & Frequency & \% \\
\hline AF with FVR & 54 & 62.79 \\
\hline AF with CVR & 28 & 32.55 \\
\hline AF with SVR & 4 & 4.65 \\
\hline Atrial Flutter-Fibrillation & 7 & 8.13 \\
\hline LVH & 36 & 41.86 \\
\hline ST-T changes (IHD) & 22 & 25.58 \\
\hline
\end{tabular}

\section{Echocardiogram Findings in AF}

During Echo study AF was present in 70 (81.39\%) patients. Ejection Fraction (EF) <50\% ie., CCF in 50 (58.14\%), RWMA in 28 (32.55\%), LVH in 38 (44.18\%) and RVH with PHT in 45 (52.32\%) patients. 27 (31.39\%) AF patients with Limbs weakness (CEIS), LA thrombus was demonstrated by TTE in $17(19.76 \%)$ and by TEE in $6(6.97 \%)$ patients. Features of LA thrombus was not demonstrated by both TTE \& TEE in $4(4.65 \%)$ patients in spite of presence of limbs weakness in them.

\section{CT Brain Finding in CEIS \& TIA in Patients with AF}

CT scan brain was taken in $29(33.72 \%)$ patients who presented with weakness of upper and lower limbs on one side of which CEIS in 27 (93\%). TIA in 2 (6.89\%) patients and they were recovered completely within 24 hours. None of the patients had evidence of intra cerebral haemorrhage.

\section{Types of AF \& its Outcome}

In this study Permanent, persistent, paroxysmal and Lone AF was detected in 65 (75.58\%), 17 (19.76\%), 3 (3.48\%) and 1 (1.16\%) patient with the survival Vs expired rate of 22 (33.85\%) Vs 43 (66.15\%), 8 (47.06\%) Vs 9 (52.94\%), 3 (100\%) Vs 0 (0\%) and 1 $(100 \%)$ Vs $0(0 \%)$ respectively. The expired rate was more than the survival rate $43(66.15 \%)>22(33.85 \%)$ in permanent AF and in persistent AF $9(52.94 \%)>8(47.06 \%)$ compared to lone and paroxysmal AF with $100 \%$ survival rate (Table 4$)$. 


\section{Aetiology for AF \& its Outcome}

In this study 1 Lone AF patient was discharged without any complication. Of the 45 (52.33\%) valvular AF, the expired rate 31 (68.89\%) was very high than the survival rate 14 (31.11\%) and in the 40 (46.51\%) non-valvular AF the expired rate 21 (52.5\%) was more than survived rate was 19 (47.5\%). Of the 40 non-valvular AF, CAHD had high expired rate 19 (55.88\%) than survival rate 15 (44.12\%) compared to Thyrotoxicosis and Alcoholic binge drinking (Holiday heart syndrome) both had best survival rate 4 (100\%) and $2(100 \%)$ without any mortality (Table 4).

\begin{tabular}{|c|c|c|c|c|c|c|}
\hline \multirow{2}{*}{\multicolumn{2}{|c|}{ Patient Characteristics }} & \multicolumn{2}{|c|}{ Frequency } & \multicolumn{2}{|c|}{ Sr. hs-CRP Level (mg/L) } & \multirow{2}{*}{$\begin{array}{c}\text { Statistically } \\
\text { Significant } \\
\text { p-Value** }\end{array}$} \\
\hline & & $\mathbf{n}$ & $\%$ & Mean + SD & Range & \\
\hline \multirow{5}{*}{ Type of AF } & Paroxysmal AF & 3 & 3.49 & $0.8 \pm 0.25$ & 0.7 to 0.9 & \multirow{4}{*}{$<0.024$ Sig } \\
\hline & Persistent AF & 17 & 19.77 & $4.33 \pm 1.62$ & 1.1 to 8.6 & \\
\hline & Permanent AF & 65 & 75.58 & $4.78 \pm 1.86$ & 1.7 to 9.6 & \\
\hline & Lone AF & 1 & 1.16 & $0.9 \pm 0$ & 0.9 & \\
\hline & Total & 86 & 100 & & & \\
\hline \multirow{3}{*}{ Complications } & Yes & 80 & 93.02 & $5.86+1.91$ & 1.2 to 9.6 & \multirow{2}{*}{$<0.001 \mathrm{Sig}$} \\
\hline & No & 6 & 6.98 & $1.35+0.72$ & 0.8 to 1.4 & \\
\hline & Total & 86 & 100 & & & \\
\hline \multirow{6}{*}{ Complications } & CCF & 50 & 58.14 & $5.33+1.08$ & 2.4 to 9.6 & \multirow{5}{*}{$\begin{array}{c}0.497 \\
\text { Not sig }\end{array}$} \\
\hline & CEIS & 27 & 31.39 & $6.27+1.24$ & 3.6 to 9.6 & \\
\hline & TIA & 2 & 2.33 & $4.85+1.42$ & $4.1 \& 5.6$ & \\
\hline & CGS & 19 & 22.09 & $6.55+2.16$ & 2.2 to 9.6 & \\
\hline & AKI & 3 & 3.49 & $7.03+2.13$ & 2.5 to 9.6 & \\
\hline & Total & $101^{*}$ & & & & \\
\hline \multirow{3}{*}{ Outcome } & Survived & 34 & 39.53 & $2.97+2.42$ & 0.8 to 5.8 & \multirow{3}{*}{$<0.001 \mathrm{Sig}$} \\
\hline & Expired & 52 & 60.47 & $6.25+1.92$ & 3.1 to 9.6 & \\
\hline & Total & 86 & 100 & & & \\
\hline \multirow{3}{*}{ Outcome } & Rate Controlled & 64 & 74.42 & $5.97+2.41$ & 0.9 to 9.6 & \multirow{2}{*}{$<0.001 \mathrm{Sig}$} \\
\hline & Rhythm Controlled & 22 & 25.58 & $3.36+1.16$ & 1 to 7.6 & \\
\hline & Total & 86 & 100 & & & \\
\hline \multicolumn{7}{|c|}{ Table 2. Sr. hs-CRP Levels and Characteristics of AF } \\
\hline & Many patients had $\mathrm{m}$ & han on & lication & ue $<0.05$ take & ficant & \\
\hline
\end{tabular}

\section{Sr. hs-CRP Level in Patients with AF}

The mean and range of Sr. hs-CRP levels was $4.78 \mathrm{mg} / \mathrm{L}$ (1.7 to 9.6), $4.33 \mathrm{mg} / \mathrm{L}$ (1.1 to 8.6), $0.8 \mathrm{mg} / \mathrm{L}$ (0.7 to 0.9) and 0.9 mg/L (0.9) in Permanent, Persistent, Paroxysmal and Lone AF respectively. Patients with AF who developed complications like CCF, CEIS, CGS, TIA and AKI with mean and range of Sr. hs-CRP level $5.33 \mathrm{mg} / \mathrm{L}$ (2.4 - 9.6), 6.27 (3.6 - 9.6), 4.85 (4.1 \& 5.6$), 6.55$ (2.2 - 9.6), 7.03 $(2.5-9.6) \mathrm{mg} / \mathrm{L}$ respectively. AF Patients with complications had high Sr. hs-CRP level than without complications. So, Sr. hs-CRP level predicts complications, survival and mortality in total and individually in a patient with AF. On admission itself 6 (6.98\%) patients with the mean and range of Sr. hs-CRP level of $1.35 \mathrm{mg} / \mathrm{L}(0.8-1.4)$ were not developed any complications during the hospital stay and one month follow up period.

$52(60.47 \%)$ patient with AF those who were expired during the hospital stay had high mean and range of Sr. hs-CRP level 6.25 $\mathrm{mg} / \mathrm{L}$ (3.1 to $9.6 \mathrm{mg} / \mathrm{L}$ ) than 34 (39.53\%) patients with AF who were survived had low mean and range of Sr. hs-CRP level 2.97 $\mathrm{mg} / \mathrm{L}(0.8$ - 5.8) which was statistically significant ( $\mathrm{p}$ value $<0.001)$. So, we can predict mortality of a patient with AF from Sr. hs CRP level on admission itself. Patients with AF, in whom the rhythm was converted to Normal Sinus Rhythm (NSR), had mean and range of Sr. hs-CRP levels $3.36 \mathrm{mg} / \mathrm{L}(1-7.6)$ is much less than in patients with AF in whom rate controlled to normal rate 5.97 $\mathrm{mg} / \mathrm{L}(0.9-9.6)$ which was statistically significant ( $\mathrm{p}$ value $<0.001$ ). So, Sr. hs-CRP level also predicts the chances of successful cardioversion, and increases the chances of maintenance of NSR, decreases the need for long term anticoagulation and its complications.

\section{Complications and Outcomes hs-CRP Risk Category in Patients with AF}

AF was more common in High Sr. hs-CRP Risk category 65 (75.58\%) patients next in Average hs-CRP Risk category 17 (19.77\%) and in Mild hs-CRP Risk category 4 (4.65\%). Expired rate also more common in AF with High hs-CRP Risk category 47 (72.31\%) than in average hs-CRP Risk category 5 (29.41\%) and survival rate was more common in AF with average hs-CRP Risk category 12 (70.59\%) than High hs-CRP Risk category 18 (27.69\%). The expired rate was more than the survival rate in high hs-CRP risk category AF patients complicated by CCF, CEIS, \& AKI with $21(56.76 \%)>16(43.24 \%), 23(85.19 \%)>4(14.81 \%), 2(66.66 \%)>1$ $(33.33 \%)$ respectively and $19(100 \%)$ deaths occurred in AF patient complicated with CGS, 2 (100\%) patients with TIA recovered fully within 24 hours (Table-3). 


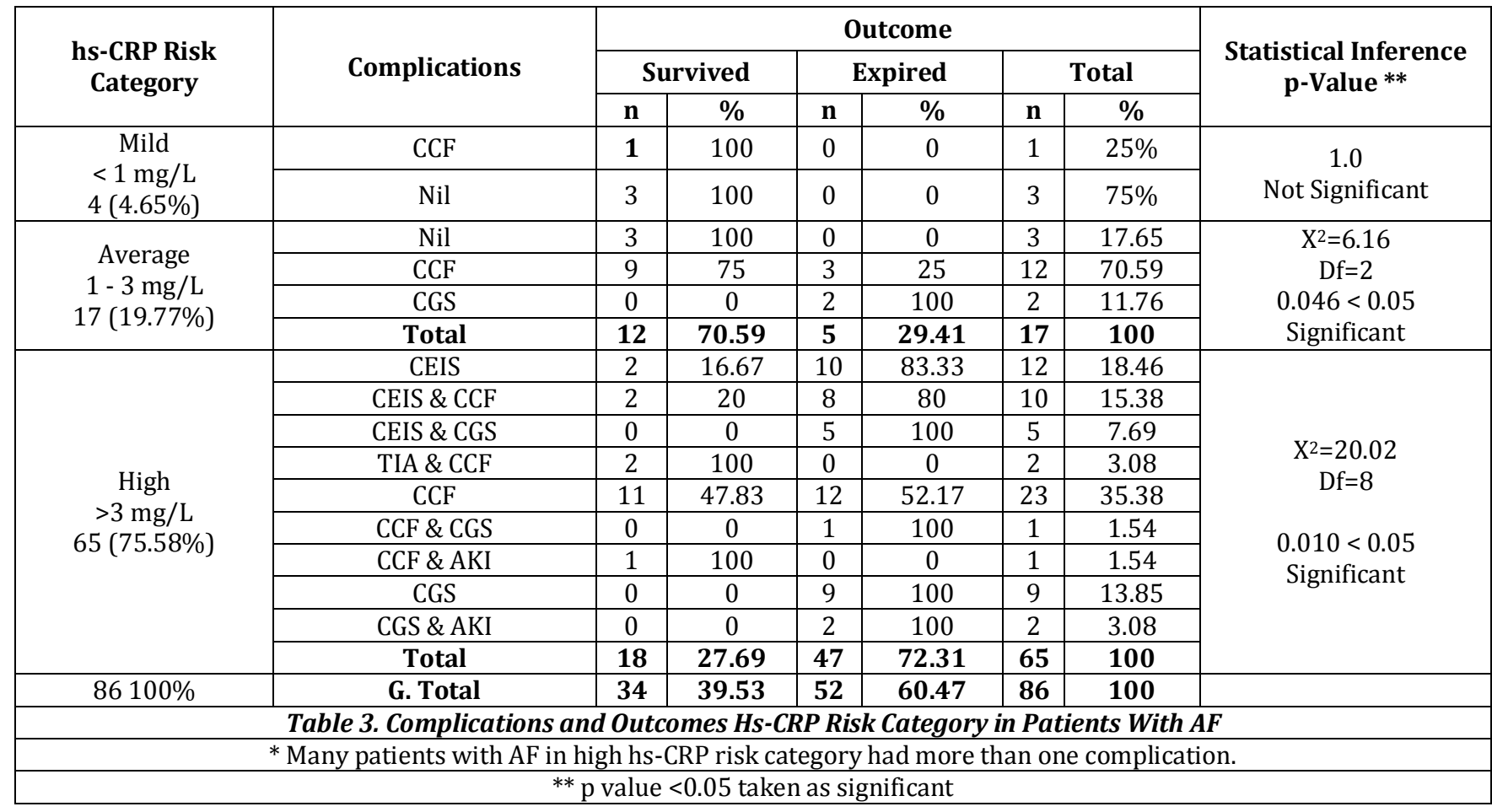

\section{Outcome of AF by Rhythm \& Rate Control}

In this study of these $86 \mathrm{AF}$ patients, AF rhythm abnormality reverted to NSR in 22 (25.58\%) patients of which 15 (68.18\%) were survived and 7 (31.82\%) were expired and AF rate abnormality reverted to normal rate in 64 (74.42\%) AF patients, of which 19 (29.69\%) were survived and 45 (70.31\%) patients were expired. (Table-4). Finally, 34 (39.53\%) patients were discharged in good condition and survived during the follow up period of one month, none of them were expired (or) developed new complications and $52(60.47 \%)$ patients expired due to various complications during their hospital stay.

\begin{tabular}{|c|c|c|c|c|c|c|c|}
\hline & \multicolumn{6}{|c|}{ Outcome } & \multirow{3}{*}{ Statistical Inference } \\
\hline & \multicolumn{2}{|c|}{ Survived } & \multicolumn{2}{|c|}{ Expired } & \multicolumn{2}{|c|}{ Total } & \\
\hline & $\mathbf{n}$ & $\%$ & $\mathbf{n}$ & $\%$ & $\mathbf{n}$ & $\%$ & \\
\hline \multicolumn{7}{|l|}{ Type of AF } & \multirow{6}{*}{$\begin{array}{c}\mathrm{X}^{2}=7.40 \\
\mathrm{Df}=3 \\
0.060>0.05 \\
\text { Not significant }\end{array}$} \\
\hline Paroxysmal AF & 3 & 100 & 0 & 0 & 3 & 3.49 & \\
\hline Persistent AF & 8 & 47.06 & 9 & 52.94 & 17 & 19.77 & \\
\hline Permanent AF & 22 & 33.85 & 43 & 66.15 & 65 & 75.58 & \\
\hline \multirow{2}{*}{ Loan AF } & 1 & 100 & 0 & 0 & 1 & 1.16 & \\
\hline & 34 & 39.53 & 52 & 60.47 & 86 & 100 & \\
\hline Aetiology OF AF & & & & & & & \multirow{8}{*}{$\begin{array}{c}\mathrm{X}^{2}=12.29 \\
\mathrm{Df}=5 \\
0.031<0.05 \\
\text { Significant }\end{array}$} \\
\hline 1) Valvular AF (RHD) & 14 & 31.11 & 31 & 68.89 & 45 & 52.33 & \\
\hline 2) Non - Valvular AF & 19 & 47.5 & 21 & 52.5 & 40 & 46.51 & \\
\hline a) CAHD & 13 & 40.63 & 19 & 59.38 & 32 & 85 & \\
\hline b) Thyrotoxicosis & 4 & 100 & 0 & 0 & 4 & 10 & \\
\hline $\begin{array}{l}\text { c) Alcohol binge drinking } \\
\text { (Holiday Heart Syndrome) }\end{array}$ & 2 & 100 & 0 & 0 & 2 & 5 & \\
\hline \multirow[t]{2}{*}{ 3) Lone $\mathrm{AF}$} & 1 & 100 & 0 & 0 & 1 & 1.16 & \\
\hline & 34 & 39.53 & 52 & 60.47 & 86 & 100 & \\
\hline \multicolumn{7}{|l|}{ Sr. hs-CRP Level(mg/L) } & \multirow{5}{*}{$\begin{array}{c}\mathrm{X}^{2}=16.79 \\
\mathrm{Df}=2 \\
<0.001<0.05 \\
\text { Significant }\end{array}$} \\
\hline Mild & 4 & 100 & 0 & 0 & 4 & 4.65 & \\
\hline Average & 12 & 70.59 & 5 & 29.41 & 17 & 19.77 & \\
\hline \multirow[t]{2}{*}{ High } & 18 & 27.69 & 47 & 72.31 & 65 & 75.58 & \\
\hline & 34 & 39.53 & 52 & 60.47 & 86 & 100 & \\
\hline hs-CRP Risk category & & & & & & & \multirow{5}{*}{$\begin{array}{c}\mathrm{X}^{2}=16.78 \\
\mathrm{Df}=2 \\
<0.001<0.05 \\
\text { Significant }\end{array}$} \\
\hline Mild & 4 & 100 & 0 & 0 & 4 & 4.65 & \\
\hline Average & 12 & 70.59 & 5 & 29.41 & 17 & 19.77 & \\
\hline \multirow[t]{2}{*}{ High } & 18 & 27.69 & 47 & 72.31 & 65 & 75.58 & \\
\hline & 34 & 39.53 & 52 & 60.47 & 86 & 100 & \\
\hline Control -Rate/Rhythm & & & & & & & \multirow{4}{*}{$\begin{array}{c}\mathrm{X}^{2}=8.60 \\
\mathrm{Df}=1 \\
0.003<0.05 \\
\text { Significant }\end{array}$} \\
\hline Rate control & 19 & 29.69 & 45 & 70.31 & 64 & 74.42 & \\
\hline \multirow[t]{2}{*}{ Rhythm control } & 15 & 68.18 & 7 & 31.82 & 22 & 25.58 & \\
\hline & 34 & 39.53 & 52 & 60.47 & 86 & 100 & \\
\hline
\end{tabular}




\section{DISCUSSION}

In this study the prevalence of AF was 39 (45.45\%) patients in the age groups of 31 to 50 years and $29(33.7 \%)$ patients in 51 to 70 years age group because of the higher prevalence of RVHD, but in Peter Libby et al study 3 the prevalence of AF is $<1 \%$ in patients of $<50$ years of age. In this study AF patients presented with dyspnoea in $72(83.72 \%)$, palpitation in 64 (74.41\%) legs swelling in 54 (62.79\%), chest pain in 49 (56.97\%), CEIS / Weakness of limbs more than 24 hours in 27 (31.39\%), weakness of limbs recovered within 24 hours without any residual weakness in $2(2.32 \%)$ which is similar to Anthony S. Fauci et al study ${ }^{1}$ and Peter Libby et al study. ${ }^{3}$

In this study CCF was present in 50 (58.14\%) AF patients and in Nicki R. Colledge et al study ${ }^{5}$ also CCF was one of the common finding with uncontrolled RVR for prolonged period of time. In this study features of valvular AF and PHT was present in 45 (52.33\%) AF patients, which is similar to Nicki R. Colledge et al study 5 and it is the common cause for high prevalence of $\mathrm{AF}$ in young patients. In this study, AF was associated with SHT and DM was in $34.88 \%$ and $17.44 \%$ patients compared to $45 \%$ and $10 \%$ in Kannel WB et al study 8 on and DM was in (17.44\%) patients may be due to the high prevalence of DM in Indians. In this study Thyrotoxicosis was present in $10 \%$ AF patients and 2\% patients in Krahn AD et al study ${ }^{9}$ and lone AF detected in $1.16 \%$ in this study and $2 \%$ in Kopecky SL et al study. ${ }^{10}$

In this study abnormal AF rhythm reverted to NSR within 24 hours (Paraoxysmal AF) in 3 (3.48\%) patients, of this 2 $(66.66 \%)$ patients had thyrotoxicosis and $1(33.33 \%)$ patient had CAHD which is similar to Kopecky S.L. et al study. ${ }^{10}$ In this study 3 (3.48\%) AF patients presented with acute onset of symptoms < 48 hours, of this $2(66.66 \%)$ patients had thyrotoxicosis, and 1 (33.33\%) patient with alcoholic binge drinking (Holiday heart syndrome) which is similar to Backer et al study. ${ }^{11}$

\section{CONCLUSION}

AF patients with high Sr. hs-CRP levels and hs-CRP risk categories were associated with increased complications and expired rate, whereas mild, average $\mathrm{Sr}$. hs-CRP levels and risk categories were associated with good survival rate and less complications. So, Sr. hs-CRP can be considered as a modifiable risk factor and biomarker to predicts complications, mortality and survival in total and individually in patients with $\mathrm{AF}$ on admission itself. Also, it predicts the chances of successful cardioversion, and increases the chances of maintenance of NSR, decreases the need for long term anticoagulation and its complications. Early detection of abnormal Sr. hs - CRP level and its complications in patients with AF by conducting camps, screening tests and treatment by life style modification, Statin drugs can improve the quality of life and decrease the complications \& mortality.

\section{REFERENCES}

[1] Fauci AS, Braunwald E, Kasper D, et al. Harrison's Principles of Internal Medicine. Vol. 2. 17th edn. McGraw-Hill 2008: p. 1427-31.

[2] Pearson TA, Mensah GA, Alexander RW, et al. Markers of inflammation and cardiovascular disease: application to clinical and public health practice: a statement for healthcare professionals from the CDC/AHA. Circulation 2003;107(3):499-511.

[3] Olgin JE, Zipes DP. Atrial fibrillation section of Specific arrhythmias: diagnosis and treatment. In: Libby $\mathrm{P}$, Robert RO, Mann DL, et al. eds. Braunwald's Heart Disease: a textbook of cardiovascular medicine. 8th edn. Philadelphia: Saunders Elsevier 2008: p. 869-73.

[4] Fuster V, Walsh RA, Harrington RA. Hurst's The Heart. $13^{\text {th }}$ edn. McGraw-Hill Professional 2011: p. 963-86.

[5] Walker B, Colledge NR, Ralston S, et al. Davidson's principles and practice of medicine. 22nd edn. Churchill Livingstone 2014: p. 82-4 \& 569-79.

[6] Feigenbaum H, Armstrong WF, Ryan $T$, et al. Feigenbaum's Echocardiography. 6th edn. Lippincott Williams \& Wilkins 2005: p. 725-27.

[7] Tillett WS, Francis T. Serological reaction in pneumonia with non-protein somatic fraction of peumococcus. J Exp Med 1930;52(4):561-71.

[8] Kannel WB, Abbott RD, Savage DD, et al. Epidemiologic features of chronic atrial fibrillation: the Framingham study. N Engl J Med 1982;306(17):1018 -22.

[9] Krahn AD, Klein GJ, Kerr CR, et al. How useful is thyroid function testing in patients with recent -onset atrial fibrillation? The Canadian Registry of Atrial Fibrillation Investigators. Arch Intern Med 1996;156(19):2221-4.

[10] Kopecky SL, Gersh BJ, McGoon MD, et al. The natural history of lone atrial fibrillation. A population-based study over three decades. $N$ Engl J Med 1987;317(11):669-74.

[11] Baker T, Nikolic G, O'Connor S, et al. Practical Cardiology. $2^{\text {nd }}$ edn. Australia: Churchill Livingstone 2008: p. 226-32. 